\title{
Trayectorias de mujeres en el hip-hop: reproducción de la vida en itinerarios de trabajo artístico
}

DOI: https://doi.org/10.18046/recs.iEspecial.3224

\author{
Women Trajectories in Hip-hop: Reproduction \\ of Life in Itineraries of Artistic Work \\ Yenny Carolina Ramírez-Suárez ${ }^{* *}$ \\ Universidad Nacional de Colombia (Bogotá, Colombia)
}

Fabián Esteban Pinzón-Díaz ${ }^{* * *}$

Universidad Nacional de Colombia (Bogotá, Colombia)

\footnotetext{
* Esta investigación se deriva del proyecto "Prácticas formativas por fuera de la escuela”, financiado por Colciencias. Como integrantes del grupo de investigación "Gobierno, subjetividades y prácticas de sí" del Centro de Estudios Sociales de la Universidad Nacional de Colombia, los autores investigaron el caso de "Ciudadanías divergentes: hip-hop y formación ciudadana en la Comuna 13". A partir del trabajo de campo desarrollado, entraron en contacto con los integrantes de Infinitos Crew, quienes participaron en las historias de vida incluidas en este estudio sobre trayectorias de mujeres en el hip-hop. La investigación se realizó en Bogotá de febrero a septiembre de 2018. Artículo de investigación recibido el 31.10.2018 y aceptado el 08.05.2019.

** Profesora del Departamento de Sociología de la Universidad Nacional de Colombia. Correo electrónico:ycramirezs@ unal.edu.co ORCID: https://orcid.org/oooo-0oo2-7632-1527

*** Sociólogo de la Universidad Nacional de Colombia. Correo electrónico: fepinzond@unal.edu.co ORCID: https:// orcid.org/oooo-ooo1-8894-5356
} 


\section{Cómo citar/How to cite}

Ramírez-Suárez, Yenny Carolina; Pinzón-Díaz, Fabián Esteban (2019). Trayectorias de mujeres en el hip-hop: reproducción de la vida en itinerarios de trabajo artístico. Revista CS, núm. especial, 137-165. https://doi.org/10.18046/recs.iEspecial.3224 
La realidad del derecho al trabajo de las artistas populares interpela los marcos tradicionales del derecho laboral. A partir de las historias de vida como fuente de conocimiento, abordamos los itinerarios de trabajo de dos mujeres dedicadas al hip-hop. Evidenciamos la complejidad de sus trayectorias y las variadas relaciones que construyen en diferentes círculos sociales. En estos espacios, toman lugar diversas formas de acumulación de capitales y saberes, y se desarrollan estrategias colectivas para la reproducción de la vida, que responden a las necesidades de protección social. A la luz de las experiencias de las mujeres, discutimos las precarias condiciones de trabajo que ofrecen las iniciativas de emprendimiento promovidas por el Estado y la cooperación internacional. Finalmente, proponemos ampliar los marcos del derecho laboral desde una comprensión del trabajo que priorice los procesos de la reproducción de la vida, mediante el sostenimiento material, la realización subjetiva y las posibilidades de participación en iniciativas colectivas de transformación social.

PALABRAS CLAVE:

derecho al trabajo, mujeres, hip-hop, trayectorias, reproducción de la vida

The reality of the right to work of popular artists challenges the traditional frameworks of labor law. Based on life stories as a source of knowledge, we review the work itineraries of two hip-hop popular artists. We present the complexity of their trajectories and the different relationships they build in different social circles. In these spaces, we find different forms of accumulation of capital and knowledge and the development of collective strategies for the reproduction of life that respond to social protection necessities. In the light of these women experiences, the article discusses the precarious working conditions offered to artists through entrepreneurial initiatives promoted by the State and international cooperation. Finally, we propose to expand labor law frameworks departing from an understanding of work that prioritizes the processes of life reproduction through material support, subjective realization, and participation possibilities in collective initiatives for social transformation.

\section{KEYWORDS:}

Right to Work, Women, Hip-hop, Careers, Reproduction of Life 



\section{Introducción}

Reflexiones contemporáneas en estudios críticos del derecho (Ahmad, 2018; Blackett, 2018) han referenciado la limitación de los marcos tradicionales del derecho laboral, para pensar las garantías de lxs trabajadorxs que se desempeñan fuera de los espacios formales del trabajo asalariado. Esta situación genera cuestionamientos acerca de los alcances y pertinencia del derecho laboral para la realidad de ciudades latinoamericanas, donde la presencia histórica de hombres y mujeres que han desarrollado trabajos diversos, en espacios y tiempos diferentes a la fábrica, ha sido una constante.

Las principales bases del derecho laboral que garantizaron la ciudadanía social a lxs trabajadorxs se gestaron en medio de los procesos de reivindicación de derechos por parte de los movimientos obreros. Los alcances de la ciudadanía social son indiscutibles, en términos de cierto avance en la redistribución de la riqueza social, a partir del acceso del trabajador a la propiedad social, vinculada a su condición salarial, bajo la cual el trabajador que carecía de bienes se volvía propietario de derechos ${ }^{1}$.

No obstante, el beneficiario de esta ciudadanía social, que inspiró las bases del derecho laboral clásico, fue el hombre de la fábrica del siglo XIX. Por fuera de este ideal, quedaron las mujeres trabajadoras que, históricamente, han asumido tareas productivas y reproductivas, en los espacios de lo doméstico. Precisamente, los estudios feministas de la economía (Carrasco, 2014; Federici, 2013; Rodríguez, 2015) han destacado la importancia de reconocer la heterogeneidad del trabajo, en términos de espacios, tiempos y oficios.

En Latinoamérica, la diversidad en el trabajo ha sido la constante y no la excepción. Los procesos de industrialización en países como Colombia nunca se generalizaron. Lo que se presentó, desde la configuración de las primeras ciudades, fue la presencia de hombres y mujeres que se trasladaban del campo a la urbe, a vender e intercambiar productos en las plazas públicas. Estas personas, provenientes principalmente de sectores rurales o de pequeñas ciudades, paulatinamente se ubicaron en las periferias y, en su condición de migrantes o de desplazados por la violencia, se integraron a la ciudad como trabajadorxs populares.

A partir del estudio del feminismo, evidenciamos la necesidad de investigar la realidad del trabajo en América Latina, desde sus condiciones concretas y de manera situada, para comprender la complejidad de relaciones y dinámicas que lo

1. De acuerdo con Castel (2009: 314), la ciudadanía social "se trata precisamente de una forma inédita de propiedad. Se inscribe en el espacio de una falta, la falta de la propiedad privada. Consiste en un basamento de derechos y de acceso a servicios no mercantiles que va a funcionar como un equivalente de la propiedad privada para garantizar a esos trabajadores un mínimo de seguridad y de protecciones 'esencial para todo ciudadano”. 
han configurado. Esto no implica renunciar a explicaciones estructurales de mayor alcance; por el contrario, lo que buscamos es indagar en la heterogeneidad de las experiencias del trabajo y repensar la pertinencia de las intervenciones del derecho laboral. Para un análisis de diferentes escalas que permita aproximarse a la comprensión de la realidad del trabajo popular, presentamos en este artículo un ejercicio de investigación que integró las reflexiones metodológicas de la microhistoria, con el trabajo de entrevistas cualitativas.

En la primera parte del artículo, exponemos las bases metodológicas que orientaron el desarrollo de la investigación. En la segunda, presentamos las historias de vida de dos trabajadoras en el hip-hop. Sus trayectorias, en algunos de los contextos donde se configuraron sus itinerarios de trabajo (el barrio, las ONG, la familia y el crew), permiten comprender su devenir en diferentes tiempos y espacios. Por último, discutimos algunos hallazgos relacionados con la pertinencia de estudiar la realidad del trabajo de las artistas populares y, mediante sus historias de vida, repensar el derecho laboral.

\section{Metodología: las historias de vida como forma de acercamiento a la complejidad del trabajo popular ${ }^{2}$}

El estudio de las prácticas populares ha oscilado entre dos tendencias: la que se concentra en la restricción y limitación de la acción; y la que hace énfasis en las cualidades de resistencia y emancipación. En el caso de lxs trabajadorxs populares, sus prácticas no se pueden comprender completamente determinadas por las formas económicas dominantes, ni configuradas como permanente respuesta a los procesos de dominación. Estos extremos en el análisis impiden abordar la complejidad y riqueza de la experiencia de las prácticas populares, cargadas de matices y contradicciones que se pueden conocer mediante el trabajo empírico (Grignon; Passeron, 1991).

El seguimiento de las prácticas concretas de los sectores populares permite descubrir sus diversas cualidades y expresiones. Aunque existe la tentación positivista de homogeneizar la caracterización de los grupos sociales, en busca de inferencias generalizadoras, los estudios de las prácticas populares, desde la microhistoria (Ginzburg, 2016; Levi, 1990), han demostrado que no existen contextos unificados que generen de manera mecánica las mismas prácticas para todas las personas. El estudio de las historias de vida, así como la biografía que propone la microhistoria

2. Agradecemos a Feback (F), a BBoy-Kapo (K), a BGirl-Bivi (B) y a BBoy-Infinito (I), artistas de hip-hop que compartieron sus historias de vida, y aportaron con su lectura y observaciones al documento de investigación. 
y que posibilita la etnografía, permiten rastrear la forma en la que el individuo es producto de su participación en múltiples contextos.

La originalidad del enfoque microhistórico radica en su rechazo a la certidumbre sobre la realidad de contextos unificados. A nivel metodológico, exige reconocer que las experiencias y representaciones sociales son múltiples, y que el recorrido de la investigación no parte de un contexto homogéneo en el que las prácticas funcionan como texto. Iniciamos la investigación a partir del rastreo de la multiplicidad de los contextos, que permite entrar al universo de los comportamientos (Revel, 1996). De esta forma, reconocemos diversas experiencias, bajo lógicas que se despliegan en medio de ambigüedades y paradojas, entre la asimilación, la resistencia y la generación de formas simbólicas propias (Hall, 1984; Levi, 2003; Passeron; Revel, 2005).

Tomar las historias de vida como camino de conocimiento no implica partir de una aproximación individualista, pues el individuo es resultado y agente de los procesos históricos que se tejen mediante su participación en diferentes contextos sociales (Ramírez, 2012) ${ }^{3}$. En tal sentido, proponemos analizar el flujo de las historias de vida en relación con los contextos sociales en las que toman lugar. Para este propósito, el concepto de itinerario nos permite analizar las trayectorias biográficas, a partir del conjunto de determinaciones inscritas en cada uno de los contextos en que se articulan las prácticas (Passeron, 2011). Estos contextos pueden ser discontinuos y desarrollar, entre ellos y al interior, diferentes relaciones de ruptura, tensión o cooperación. Así, la historia de vida como herramienta para la investigación, nos lleva a seguir al individuo en la madeja de espacios-tiempos que teje la interrelación de diferentes contextos de referencia en los que la individualidad va tomando forma.

En el trabajo de contextualización múltiple de las historias de vida, no existe oposición entre la historia local y la global; por el contrario, se comprende que el individuo "participa de cerca o de lejos, en procesos -y entonces se inscribe en contextos- de dimensiones y niveles diferentes, del más local, al más global" (Revel, 1996: 30). Esto conduce a lo que la sociohistoria ha denominado "relaciones a distancia", como procesos sociales e históricos que se comprenden en el análisis relacional de los contextos, y de los que se puede tener indicio, a partir del estudio de las historias individuales. Las relaciones a distancia sobrepasan la esfera de los intercambios directos, en tanto que las dinámicas colectivas vinculan a millones de personas que no se conocen (Noirier, 2011).

3. En esta misma dirección, en las investigaciones de la microhistoria, Ginzburg (2007: 13) aborda al individuo como "el punto de intersección de toda una serie de conjuntos diferentes, que tienen cada uno dimensiones variables". 
Bajo estas orientaciones, desarrollamos la investigación de dos historias de vida de mujeres que trabajan en la cultura hip-hop. En el seguimiento de sus relatos, destacamos los contextos del barrio, la familia, las ONG y el crew, como espacios-tiempos comunitarios e institucionales que permiten comprender el sentido y curso de los diferentes momentos de las trayectorias biográficas. Al planear el estudio de trayectorias de mujeres en el hip-hop, inicialmente, consideramos indagar las historias de vida de mujeres en la comuna 13 de Medellín, donde, previamente, habíamos realizado observaciones y entrevistas etnográficas a colectivos de este movimiento artístico.

Sin embargo, aunque en la comuna 13 es posible encontrar valiosas expresiones, como las del grupo familiar La Mamá Rapera, son muy escasas las artistas hopperas en el territorio. El hip-hop en esta comuna se inscribe en una cultura masculina. Fue a través del contacto con algunos de los integrantes de Infinitos Crew, grupo que desde hace más de diez años realiza sus prácticas de break dance en el Parque Biblioteca San Javier, que logramos contactar a las mujeres que inspiraron las historias de vida de este ejercicio de investigación. Las entrevistas ${ }^{4}$ las desarrollamos a partir de las relaciones de interconocimiento de los integrantes del grupo y de sus parejas, lo que nos permitió acercarnos a la comprensión de ciertas lógicas colectivas que se tejen al interior de los círculos sociales (Weber; Beaud, 2010). En este sentido, la presentación de las entrevistas de las mujeres se apoya con los relatos de sus parejas, que posibilitan ver puntos en común y contrastes en las trayectorias.

\section{Feback: itinerario artístico desde el barrio}

Feback 5 es una mujer de 30 años, residente en la ciudad de Bogotá. En su adolescencia, vivió en el barrio El Codito ${ }^{6}$ y conoció el hip-hop en un colegio público de la localidad de Usaquén. La reunión con Feback se dio a través de su pareja, BBoy-Kapo, artista

4. En relación con la importancia de la entrevista como fuente de conocimiento, y no simplemente como insumo para comprobar teorías abstractas, retomamos los aportes metodológicos presentados en $L a$ miseria del mundo (Bourdieu, 1999), donde se expone un seguimiento de los hallazgos de la investigación, a partir de la exposición completa de las entrevistas. Aunque, por limitaciones de espacio, en el artículo no se presenta el registro total de las entrevistas, se conservan apartes completos de diferentes asuntos, para facilitar la comprensión de las historias.

5. De acuerdo a lo expresado por ella misma, su nombre artístico significa "la fe que vuelve".

6. El Codito es un barrio ubicado en los cerros nororientales de Bogotá. La mayor parte de las viviendas hacen parte de los estratos 1 y 2, y son producto de procesos de autoconstrucción de la población proveniente de zonas rurales andinas del país, que, paulatinamente, llegó a la ciudad a causa de desplazamiento forzado o en busca de mejores condiciones socioeconómicas. 
de 34 años, quien ha dedicado la mitad de su vida a la práctica del break dance; lo conocimos en el Parque Biblioteca San Javier, en la comuna 13 de Medellín.

Feback nació en el municipio de Vélez, Santander ${ }^{8}$ y llegó con su familia a Bogotá, desplazada por la violencia, en 1997. Se ubicaron en el barrio El Codito, donde creció y trabaja, hasta el presente, en procesos colectivos inspirados en la cultura hopper. Por solicitud de ella y de BBoy-Kapo, acordamos hacer la entrevista en el Centro Histórico de La Candelaria, punto intermedio entre su lugar de trabajo, en El Codito, y el de vivienda, en el Portal de las Américas (localidad de Kennedy). Previamente, habíamos hecho contacto con BBoy-Kapo, en Medellín, y habíamos conversado con su amigo BBoy-Infinito, lo que contribuyó a generar un ambiente de confianza y cordialidad.

Antes de iniciar la conversación, BBoy-Kapo consultó la lista de resultados de una convocatoria distrital de apoyo a proyectos culturales locales, en la que habían sido seleccionados. Feback comentó que su proyecto consistía en promover prácticas culturales alrededor del lema "Hip-hop libre de sexismos". Ya habían impulsado iniciativas similares, desde que constituyeron, en el barrio El Codito, una organización con la que siguen gestionando proyectos de intervención cultural.

\section{El encuentro con el rap en El Codito}

El barrio ha sido el espacio por excelencia donde se ha alzado la voz del hip-hop. Desde sus primeras expresiones, en los barrios afroamericanos de Nueva York, este movimiento ha reivindicado la vida cotidiana de sus habitantes y ha dejado en evidencia sus precariedades, pero también su creatividad y fuerte potencial de vida. En Colombia, en los barrios populares han surgido importantes iniciativas

7. La comuna 13 es un territorio ubicado en las laderas occidentales de Medellín. La mayoría de los barrios que la componen se encuentran en los estratos 1, 2 y 3 . Esta comuna ha sido habitada, principalmente, por población migrante y desplazada por la violencia. En la década de los noventa, vivió intensas situaciones de violencia relacionadas con la presencia de milicias urbanas de grupo guerrilleros y paramilitares. Además, se destaca en la historia del conflicto armado en Colombia, porque, en 2002, en Estado de excepción, fue bombardeada y tomada mediante numerosas operaciones por fuerzas militares, policía y paramilitares, bajo pretexto de reestablecer la seguridad y el orden (Centro Nacional de Memoria Histórica [CNMH], 2011).

8. Este municipio se encuentra ubicado al sur del departamento de Santander. Históricamente, este territorio se caracterizó por la presencia del liberalismo radical que, en su enfrentamiento con las facciones conservadoras, llevó al desplazamiento forzado de numerosos habitantes de la región. En la década de los noventa, enfrentó el impacto del conflicto armado entre la guerrilla de las FARC y grupos paramilitares, presentes en el área del Magdalena Medio (Vargas, 1992). 
de hip-hop ${ }^{9}$, en barrios ubicados en comunas como la 13 y la 4, en Medellín, o en localidades como Kennedy, Engativá y Ciudad Bolívar, en Bogotá, en las que han emergido múltiples grupos de rap y grafiti.

Desde el inicio de la entrevista con Feback, las referencias al barrio fueron recurrentes. Al preguntarle acerca de la forma en que conoció el hip-hop, ella comentaba que llegó al rap, gracias al encuentro con unos compañeros de Engativá, que estudiaban en su mismo colegio:

\section{E: ¿Dónde estudiabas?}

F: Yo estudié toda mi primaria en la localidad de Usaquén, no era específicamente en El Codito, porque en ese entonces no había colegio ahí, el colegio quedaba en la 165 con séptima, se llama Agustín Fernández. Entonces, yo tenía que trasladarme siempre a esa parte de la localidad para poder estudiar. Entonces, empecé a conocer a los que fueron mis amigos de décimo y once, con los que empecé a entender como toda una práctica que ellos tenían. Uno de ellos venía de Engativá a estudiar ahí, y ellos tenían un grupo que era muy revolucionario, entonces yo me acuerdo que las canciones que hacían eran revolucionarias (Feback, comunicación personal, 07.2018).

La experiencia en el colegio evidencia las limitadas condiciones de la educación pública y su cobertura de cupos. En Bogotá, cuando en una localidad no se alcanzan los cupos para todos los estudiantes que demandan entrar, se les ubica en otros espacios; en este caso, al estudiante de Engativá, le asignaron el cupo en la localidad de Usaquén. Este hecho, infortunado para el estudiante, en términos de movilidad y lugar de origen, dio paso a relaciones inesperadas entre habitantes de diferentes territorios, afines en términos de condiciones socioeconómicas de barrios populares, pero con historias diversas. En Usaquén no existía la tradición de hip-hop que ya llevaba años en Engativá.

El barrio es el lugar en el que cotidianamente habitan los "parches" de rap y break. Allí se configuran redes de aprendizaje tejidas entre pares. Tanto BBoy-Kapo, como Feback y BBoy-Infinito (líder del grupo Infinitos Crew), coinciden en que se motivaron a avanzar en la práctica, a partir de reuniones para ver videos, y realizar

9. El hip-hop emerge como movimiento contracultural a inicio de la década de los 70 en los barrios marginales, habitados por negros e hispanos en Nueva York. Desde sus inicios, las expresiones artísticas del hip-hop buscaron visibilizar las condiciones de desigualdad social y precariedad en las que vivían sus habitantes. El hip-hop está compuesto por cuatro disciplinas: deejaying (manipulación de música pre-grabada), break-dancing (danza basada en movimientos en el piso), rapping/emceeing (vocalización) y graffiti (arte visual). Estas cuatro manifestaciones artísticas fueron articuladas por el líder Afrika Babbata en una propuesta de desarrollo social alternativa para los jóvenes que se enfrentaban en pandillas en la ciudad (Higgins, 2009). 
juntos los movimientos que hacían los artistas. Tal como le ocurrió a Feback, quien se animó a practicar rap cuando un amigo le mostró un video en el que aparecía una mujer cantando:

\section{E: ¿Cómo te animaste a hacer hip-hop?}

F: Un día, después del colegio, quedamos de ir a hacer almuerzo para poder hacer una exposición, recuerdo tanto que era de ciencias políticas. Entonces, yo le dije a un amigo del colegio: "Oye, no tienes videos, yo quiero ver videos de otros grupos"; y él me dijo: "Sí, ven”, entonces puso el video y apareció Makiza; cuando yo veo a Anita rapeando con ellos, como que superengomada con el tema de toda la historia, y escuche tanto... La canción se llama La rosa de los vientos, y claro... (sonríe). Entonces, la forma en que ella rapeaba, cómo la hacía, y cómo se igualaba al mismo nivel de sus compañeros de grupo me motivó muchísimo. Entonces, ese mismo día yo les dije a ellos: "Vengan, yo quiero empezar a rapear, enséñenme”, y ellos, pues obviamente, siempre fueron muy dispuestos a que yo aprendiera. Entonces me pasaban libros, me decían: "Tienes que leer mucho, tienes que entender que no es solamente la música, de pronto no estás sola, hay más en Bogotá como tú, pero entonces hazlo”.

Y ese hazlo fue meterme en un mundo completo; ya yo me la pasaba con mis canciones, no dormía, me la pasaba escribiendo en todo momento, creo que fue como un despertar de esa palabra que tenía adentro. De también contar la historia de mis papás, de entender y denunciar las condiciones en que vivíamos que, pues, de una u otra forma, eran muy difíciles, en un noventa por ciento, mi vida era sola, o sea, yo salía del cole, mi mamá trabajaba, pues, en casas, haciendo limpieza, aún lo sigue haciendo, y mi papá, pues... decidió irse de celador a una finca. Entonces, todo el tiempo yo estaba sola, yo estaba era al cuidado de mis amigos, y de la señora del restaurante comunitario. Entonces, era hacer algo productivo con mi tiempo, y el rap se convirtió en eso, en una práctica que, a pesar de aprovechar el tiempo libre, también me nutría muchísimo (Feback, comunicación personal, 07.2018).

En la historia de Feback, el barrio es significativo de diferentes maneras. Con la precarización del trabajo de los y las integrantes de las familias, y la ausencia de oferta pública de actividades extracurriculares, las condiciones para el cuidado de niños y niñas, en estos sectores, son limitadas. No obstante, desde las dinámicas en las que Feback vivía desde su práctica de rap, se configuró en el barrio un espacio de cuidado colectivo, en medio de la escasa presencia de institucionalidad pública. Mientras la madre de Feback trabajaba como aseadora de casas, y las madres de sus compañeros se ocupaban, de igual forma, en trabajos precarios, ellos se cuidaban mutuamente en el espacio público del salón comunal, que funcionaba también para actividades del hospital. Se puede observar, en esta situación, una articulación entre 
prácticas e instituciones relacionadas con la reproducción social ${ }^{10}$, que sostienen cotidianamente la vida laboral de la ciudad, mediante la respuesta comunitaria a los problemas de la salud y el cuidado, ante la deficiente provisión, por parte del Estado, de los derechos asociados a la protección social:

F: Empezamos a reunirnos después del colegio en el salón comunal, y empezaron a llegar muchos, muchos, muchos chicos; chicos que hacían grafitis, chicos que hacían break, o sea, empezó a convertirse como en un proceso, en que salíamos del colegio y nos reuníamos, y empezó a convertirse en un lugar sagrado para nosotros, o sea, nosotros de seis de la tarde a nueve de la noche, todos estábamos allá metidos en ese salón, o sea, las mamás llegaban a buscarnos allá.

E: ¿Podían usar sin problema el salón?

F: Sí, pues, era un salón que funcionaba en el día de atención médica. Era un salón chiquito y ahí nos reuníamos a rapear. Y el hospital nos dijo que querían hacer una canción para una campaña de salud, con el tema de la prevención del embarazo, y nosotras dijimos: "Nosotras la hacemos...”, y ese fue nuestro primer concierto, frente al barrio (Feback, comunicación personal, 07.2018).

En contraste con la relación afirmativa de Feback con el barrio, la relación de BBoy-Kapo y BBoy-Infinito con la comuna 13 ha experimentado contradicciones que alimentan distancias y cercanías. A partir de la práctica colectiva en el Parque Biblioteca San Javier, Infinitos Crew se ha constituido, hasta el presente, en un espacio alternativo para el manejo del tiempo, la generación de dinámicas en contra de la violencia y la construcción de sentido para los jóvenes de la comuna ${ }^{11}$. Al respecto, señala BBoy-Kapo:

10. En adelante, tomaremos el concepto de reproducción social como las actividades y relaciones directamente involucradas en el mantenimiento de la vida cotidiana de las personas en diferentes generaciones. Estas involucran trabajos socialmente necesarios -mentales, físicos y emocionales- dirigidos a proveer y mantener la reproducción de la población. La reproducción social incluye las prácticas y procesos mediante los cuales la comida, el vestido y la vivienda están disponibles para el consumo inmediato; así como las formas en las que se atiende el cuidado de los niños y los adultos mayores (Benzason; Luxton, 2006). Esta reproducción social, mediante el trabajo reproductivo, asumido en la mayoría de los casos por mujeres, sostiene la acumulación en el sistema capitalista y toma lugar en espacios como los hogares, hospitales y escuelas (Ferguson, 2017).

11. Para profundizar en los procesos de transformación social promovidos por Infinitos Crew en la comuna 13, Ver https://infinitoscrew.com/videos 
E: ¿Cómo fue encontrarse con el break en la comuna 13?

K: Pues, allá había mucha delincuencia, mucha guerra, más que todo, pues, luchando por el territorio los muchachos, peleando por su territorio, pero igual, como dice uno, uno anda callado, sin meterse con nadie, uno iba solo a la práctica, de vez en cuando la gente decía: “¿Qué hace?, que ¿para dónde va?”, y, simplemente, uno contesta: “Voy a ir a ensayar, voy a ir a la práctica”, y ya, simplemente eso, es como cuando a uno le gusta hacer algo y ya, no meterse con la gente del barrio ni hacer nada que tenga que ver con eso (BBoy-Kapo, comunicación personal, 07.2018).

Desde sus primeras expresiones en Nueva York, el hip-hop representó una opción de vida para lxs jóvenes afrodescendientes, habitantes de barrios marginados (Higgins, 2009). De acuerdo con Arias (2014), el hip-hop convocó, en sus inicios, a artistas y activistas mediante los principios fundadores de la cultura: paz, amor, unidad y sano esparcimiento. Al amparo de estos ideales, se buscaba encontrar opciones de convivencia, en barrios en los que el tráfico de drogas y la criminalidad eran la realidad cotidiana.

La relación con el barrio de Feback, BBoy-Kapo y BBoy-Infinito, a pesar de desarrollarse en sectores populares y de tener como punto en común la cultura hip-hop, evidencia matices en la experiencia. Los casos de BBoy-Kapo y BBoy-Infinito, en las difíciles condiciones de violencia de la comuna 13, contrastan con el de Feback en El Codito, un territorio afectado por la violencia socioeconómica y criminal, e impactado por el conflicto armado, aunque con menor intensidad. Los relatos de estxs artistas dejan manifiestan la influencia de las dinámicas de violencia y sus posibles variaciones, en la significación y las relaciones tejidas con el barrio, alrededor de la práctica del rap y del break dance.

\section{Las inciertas lógicas laborales en la ONG}

Feback nos relató su encuentro en el barrio con dos amigas con las que creó el grupo Tercera Cuadra, nombre que proviene de "juntar los puntos de sus casas, con los que se formaba una línea vertical” (Feback, comunicación personal, 05.2018). Con Tercera Cuadra se presentaron en diferentes eventos culturales organizados por el distrito y buscaron en una fundación la oportunidad para grabar sus canciones:

F: Cuando ya nos empezamos a aterrizar en el proceso, empezamos a entender que todo era dinero. Entonces, un productor nos dijo: "Les voy a regalar una canción, pero ustedes tienen que grabar el resto, y la mejor canción va para mi disco”. Claro, para nosotras era levantarnos y pensar cuánto dinero nos faltaba para poder llegar a 
la Fundación, con el dinero para poder grabar las canciones y aprovechar que él iba a estar ese tiempo en Bogotá, para poder hacer eso. Nos metimos en líos, yo me metí en una cosa loquísima, yo dejé de ir a estudiar prácticamente un mes, porque salió una vaina, las famosas captadoras-bolsas de empleo, yo decía: "Tenemos que buscar un empleo", y yo era la mayor de edad entre ellas. Entonces, voy a buscar un empleo, y ¿cómo yo reúno la plata?

Entonces me metí en una vaina así reloca. Yo recuerdo que era aquí en el centro, tenía capacitaciones en la mañana, pero, pues, al fin y al cabo era una estafa, porque me daban unos perfumes y, sí yo vendía los perfumes entraba a la empresa, y si no vendía, no; fue terrible, terrible... Y Sandra vendía dulces en la universidad, también estaba prohibido, entonces fue la locura y en las tardes nos reuníamos para camellar en los buses, terminábamos a las diez de la noche, mamadas, pero motivadas, hasta que reunimos el dinero. Entonces cuando, claro, reunimos el dinero, nos fuimos de una vez para el estudio (Feback, comunicación personal, 07.2018).

Feback narra su experiencia en trabajos precarios, como la venta de perfumes con la captadora y el canto de rap en los buses, opciones a las que accede sin poseer estudios universitarios ni capital social para ubicarse en condiciones de trabajo más estables.

\section{E: ¿Te contrataron en la Fundación?}

F: Me contrataron en la Fundación y empecé a dar clases en hogares Claret, era un hogar de paso que quedaba frente de La Ele. Trabajé doce años con ellos, pero cuando ya empezó como un tema político, decidí alejarme, cuando ya empezó como a haber mano política de politiqueros dentro de la organización, decidí como, no, esto no es el hip-hop; por más que sea político, pero no es politiquero, entonces decidí alejarme de la fundación y el año pasado renuncié. Entonces fue como todo un proceso de crecimiento.

E: ¿Y durante esos doce años, te contrataron?

F: Sí, durante esos doce años yo viví del hip-hop, o sea, viví generando procesos formativos, creé herramientas metodológicas, fomenté todo el tema de la lectoescritura con rap, entonces, de una u otra forma, el rap se convirtió también, para mí, como en una herramienta de transformación social. Entonces, no era yo la rapera, sino era toda mi acción social y comunitaria con el rap, entonces yo no puedo vivir solo dando conciertos y cantándole y tener toda la gente que quería tener cuando estaba más pequeña, sino que también quería tener, yo hablaba, decía: "Quisiera tener un -va a sonar chistoso-, un ejército de seres humanos que estén empoderados de sí mismos, que tengan amor propio, que tengan todo el tema superclaro de la resistencia, por el territorio y el barrio”, porque empecé a ver que eso faltaba. 
Entonces, claro, tenía a mi amigo que todo el tiempo se vivía quejando por que no tenía trabajo, todo el tiempo le echaba la culpa al barrio, de que no tenía oportunidades. Yo decía: “Bueno, si ese es su problema, ¿por qué no las buscamos?”, por eso decidíaprender mucho de la Fundación, en el tema de formulación de proyectos; tuve la oportunidad de viajar, de hacer intercambio de experiencias a Brasil, a Holanda, a Panamá, estuve en la ONU, en un grupo de mujeres, hablando sobre el panorama de la mujeres a nivel de Latinoamérica. O sea, libré unas peleas también fuertes de entender el movimiento como una forma de razón de vida, más que ser una experiencia civil de la gente que se movilice por esto, es que es una razón para levantarse cuando uno no tiene esperanza de absolutamente de nada; y eso pasa mucho, y eso me lo enseñaron los niños de los hogares Claret, los niños hermanos de mi barrio (Feback, comunicación personal, 07.2018).

La Fundación es una organización de la sociedad civil, constituida en 1996 alrededor de la cultura hip-hop, con sedes en Bogotá y Cali. Sus proyectos culturales son financiados por instituciones públicas y por organizaciones de cooperación internacional; de estas últimas provienen la mayor parte de los recursos que han posibilitado su sostenimiento durante más de veinte años. La experiencia de Feback en la Fundación ayuda a pensar en el lugar ocupado por la ONG y su relación con las dinámicas del trabajo.

Reflexiones acerca de la intervención transnacional han problematizado el papel de las ONG en el gobierno de los países que reciben cooperación (Morss, 1984; Barry; Osborn; Rose, 1996; Ferguson; Gupta, 2002). De acuerdo con estos estudios, las ONG, aunque se presentan como organizaciones no gubernamentales, desarrollan una función central de gobierno, porque, desde unas dinámicas transnacionales: posicionan ciertas agendas, entran en el juego institucional de la intervención social y, en la mayoría de los casos, debilitan la relación de exigencia de derechos del ciudadano con las instituciones públicas estatales (Barry; Osborn; Rose, 1996). Para Ferguson y Gupta (2002), la dinámica local de las ONG es expresión de un poder nacional, regional y de fuerzas globales. La cooperación internacional toma lugar en lo local, pero su lógica se articula a nivel trasnacional, ejemplo de ello son organizaciones como USAID, Young Men's Christian Association (YMCA), Open Society o Empower, entre otras, financiadoras de los proyectos de intervención social de la Fundación.

El debilitamiento de la relación de derechos del ciudadano con el Estado surge de las relaciones de dependencia que generan las intervenciones tipo proyecto. Su lógica transitoria desdibuja transformaciones estructurales de fondo, genera conflictos tanto de los actores intermediarios como entre los receptores por los recursos, y dispone hacia prácticas clientelares. Precisamente, esta última problemática fue la 
que motivó la renuncia de Feback a la Fundación, pues el presidente se vinculó en la competencia política electoral desde un partido político tradicional, lo que, para ella, iba en contravía de los intereses políticos que defendían los jóvenes hopperos en los territorios populares. A Feback, el presidente le pidió facilitar la promoción política de su campaña, en los espacios de formación que acompañaba desde la Fundación. Ella manifestó su desacuerdo con utilizar dichos espacios para ese propósito, y recibió la noticia de una reducción de salario, que la llevó a renunciar a su trabajo. En su relato, Feback comentó que ese suceso generó rupturas en la organización, las cuales, al presente, han conducido a un importante debilitamiento del trabajo de la Fundación con las bases de jóvenes.

No obstante, dentro de la complejidad de funcionamiento del gobierno transnacional de la cooperación y la intervención mediante proyectos, es necesario destacar que la recepción por parte de los beneficiarios no es pasiva, incluso en la operación que adelantan organizaciones intermedias como la Fundación, a nivel nacional. Feback destaca las metodologías de creación y debate generadas dentro del margen de maniobra de esta fundación, mediante las cuales ella sintió que se impulsaban procesos críticos en lxs participantes. Para Feback, el hip-hop se convirtió en un campo de trabajo, en el que, además de conseguir los recursos para su sostenimiento material, encontró una fuente de sentido en la articulación del trabajo artístico y creativo con los procesos de transformación social. Hoy, Feback es madre de un bebé y lidera el proyecto de "Hip-hop libre de sexismos", desde una organización local. Este proyecto busca generar cuestionamientos acerca de las relaciones de género y las múltiples formas de vivir la sexualidad en el territorio, a partir de las prácticas del break dance, el grafiti y el rap.

\section{BGirl-Bivi: posiciones de clase y profesionalización en el crew}

En el mismo círculo de interconocimiento de Infinitos Crew, conocimos a BGirl-Bivi. El encuentro con ella generó preguntas y complejizó la comprensión de las trayectorias artísticas en el hip-hop, por su particular historia de vida. BGirl-Bivi es una joven de 31 años que nació en Bucaramanga, hija de una madre que estudió artes plásticas en la Universidad de la Sabana, en Bogotá, y que se mudó a Bucaramanga, por los compromisos de trabajo de su esposo. Estudió Negocios Internacionales, en EAFIT, la universidad privada más prestigiosa de Medellín, y llegó al hip-hop por una búsqueda subjetiva en la danza. Actualmente, reside en la ciudad de Bogotá, en donde se realizó la entrevista, junto con su pareja, BBoy-Infinito, y su hija de dos años. 


\section{Capitales heredados y encuentro del break dance en la institucionalidad comercial}

La familia ocupa un lugar muy importante en la historia de BGirl-Bivi. Su madre la familiarizó con el mundo del arte y, en su hogar, encontró múltiples posibilidades de formación para cultivar prácticas corporales y deportivas. En la escena del break dance colombiano, es frecuente encontrar grupos constituidos por hombres. No obstante, en los últimos años han empezado a aparecer algunos de mujeres, como los que apoyan Feback y BBoy-Kapo en El Codito. El break dance exige gran fuerza física para lograr sostener sus exigentes movimientos. Sin embargo, con la trayectoria de capital deportivo acumulado por BGirl-Bivi desde su infancia, ella logró entrar a Infinitos Crew. Al respecto, ella señala:

\section{E: ¿Cómo llegas a hacer break dance?}

B: Empecé a bailar desde los cuatro años, siempre me llenó el deporte. Yo hago ejercicio con mi mamá desde los dos años, ella hacía ejercicio en la casa, así, con videos, y yo hacía ejercicio con ella, y yo la acompañaba. Entonces, siempre me ha gustado la parte del ejercicio físico, el deporte siempre, y desde pequeña yo estuve en natación, en patinaje, en atletismo. En el colegio, estaba en grupos de básquet, en todo... yo alcancé a competir a nivel nacional en natación y en patinaje también. Entonces, siempre me gustó mucho la parte del deporte, entonces siempre he sido muy de físico, de ejercitarme; empecé como con eso, y con el baile también a la par. En el colegio, yo estaba en el grupo de baile, siempre me gustó eso, desde el colegio yo hice la parte del deporte y la parte de baile y, de hecho, yo quería ser bailarina de ballet.

Por cosas de la vida, no me aceptaron en la academia, en la única academia que había así en Bucaramanga, y me dijeron que no, no me aceptaron que dizque porque yo tenía la espalda muy ancha, entonces que no, tenían unas cosas absurdas de que las niñas tenían que ser así, y no sé qué... entonces no me aceptaron en la academia. Yo seguí más con lo otro y cuando me fui a Medellín, cuando terminé el colegio, yo dije: "Bueno, en Colombia no hay profesión de danzas, no lo hay, no lo puedo hacer por fuera, entonces lo voy a seguir haciendo empírico y, a la par, voy a hacer mi carrera profesional”, porque sí, en mi casa me decían: “iUsted qué va a vivir del baile!, jeso no es una profesión!, ¿dónde va a vivir?, no sé qué, etcétera...”. A pesar de que mi mamá es licenciada en artes plásticas, ella tomó la decisión de ser ama de casa, no vive del arte (BGirl-Bivi, comunicación personal, 03.2018).

BGirl-Bivi cultivó en su infancia, un capital deportivo y artístico que contribuyó en su interés por continuar la práctica de la danza, además de sus estudios académicos profesionales. El rechazo que enfrentó en la academia de ballet, donde 
predominaban unos criterios respecto al cuerpo femenino que no se ajustaban a su constitución física, redireccionó su mirada a la exploración de otras danzas urbanas, diferentes a la clásica. A pesar de la formación de su madre como artista plástica, ella le recomendó a su hija estudiar una carrera universitaria y desistir de dedicarse a la danza como profesión. El imperativo de estudiar una carrera profesional de éxito era una exigencia que, difícilmente, BGirl-Bivi podía discutir en su familia, en una clase social media-alta, donde el mínimo requisito de una trayectoria exitosa era ir a la universidad. Para BGirl-Bivi fue imposible renunciar a los estudios universitarios. En contraste, Feback se retiró de la carrera de comunicación social en la Universidad Los Libertadores lo que generó traumatismo en la relación con su madre. Ella le ayudaba a financiar sus estudios de comunicación social mediante su trabajo como aseadora de casas y, probablemente, tenía la esperanza de contribuir a que su hija lograra conseguir mejores opciones de trabajo.

La historia de infancia de BGirl-Bivi contrasta con la de su pareja, BBoy-Infinito, quién creció en la comuna 13, en una familia separada y con limitados recursos económicos. Respecto a su infancia y encuentro con el break dance, él relata:

\section{E: ¿Cómo llegaste al break?}

I: ...A mí nunca me ha gustado como los deportes, nada de esto y, si me llamaban la atención, no había forma económica de acceder a ellos, éramos muy pobres. Cuando mis papás se separaron, mejor dicho ahí sí, y entonces, no uno, jah!, entonces yo montaba cicla y no podía tener una cicla buena. Uno era como muy cerrado, y yo no tenía buenos frenos para mi cicla, y yo dejé eso, y yo creí que me iba a morir hasta que conocí el break (BBoy-Infinito, comunicación personal, 03.2018).

BBoy-Infinito no contó en su infancia, con las condiciones socioeconómicas para cultivar la práctica de un deporte, como sí lo hizo BGirl-Bivi. Pero, al igual que Feback, en el barrio se encontró con la incipiente cultura hip-hop que se gestaba a principios de la década del 200o, en diversos sectores populares de Bogotá y Medellín. $\mathrm{Al}$ revisar la historia de este movimiento (Higgins, 2009), advertimos que varias de las características que configuraron su cultura, como el uso de vinilos, por ejemplo, surgió a partir del reciclaje de tocadiscos desechados y reutilizados por los primeros disc-jockey; el aprendizaje entre pares tomó lugar ante la imposibilidad de pagar clases especializadas de una danza que se renueva en la improvisación que ocurre en la experimentación circular del crew. Estos elementos provienen de ciertas posibilidades creativas-comunes en lo popular-, que han emergido en condiciones de restricción. 


\section{Tránsitos de clase y profesionalización del crew}

BGirl-Bivi realizó sus estudios universitarios en Medellín. Vivía en El Poblado y estudiaba en la Universidad EAFIT ${ }^{12}$. Junto a su formación académica, siguió clases de danza en academias privadas, practicó ritmos urbanos y profundizó en el break dance. Se encontró con Infinitos Crew a través de Checho, profesor de break de una de las academias privadas y amigo de barrio de BBoy-Infinito. Desde la práctica con Checho, BGirl-Bivi asistió a una competencia en la que conoció a BBoy-Infinito. En este evento, se presentó el cruce de diferentes grupos sociales: Infinitos Crew (comuna 13) y Urban Flow (academia de danza, comuna El Poblado). Lo que significó este encuentro alrededor de la práctica del break dance fue la confluencia de la práctica popular de barrio con la práctica de élite de la academia privada. Desde entonces, BGirl-Bivi se integró a la práctica de break dance en la comuna 13:

E: ¿Empezaste a ir los domingos a San Javier?

B: Empecé a ir los domingos a San Javier y empecé a conocer el proceso que BBoy-Infinito tenía ahí... Nos encarretamos como pareja, y empecé a involucrarme mucho más en lo que él hacía, a ver más el proceso que él tenía en San Javier. Empecé a ayudarle más a él en eso y a buscar profesionalizar todo lo que ya tenía, entonces, ya empecé a investigar más. Como yo estudié Negocios Internacionales y estaba terminando la carrera, siempre he querido combinar las dos, la parte de negocios con el arte. Yo creo que el arte por ser callejero o por ser empírico no debe dejar de ser profesional; uno también tiene que llevar esa parte artística a un nivel profesional, entonces empecé a ver más lo que ellos hacían y a investigar y a ver proyectos, y a investigar cómo poder tener más ingresos de eso, y fue cuando empezamos a mirar lo de los proyectos. Empezamos a ver eso, convocatorias, proyectos y los empecé a llevar a ellos, como: "Miren, esto se puede hacer así", la parte más profesional, poner un nombre, saquen un logo, saquen tarjetas, ya ellos hacían todo así como muy informal. Entonces, yo los empecé más como a encaminar, "Mira, hagámoslos así, por qué no hacemos esto...” (BGirl-Bivi, comunicación personal, 03.2018).

BGirl-Bivi desarrolló una relación de intercambio de saberes con el crew, ella le aportó sus conocimientos en el área de negocios y este se convirtió para ella, en un espacio de trabajo organizativo y de desarrollo técnico como artista, mediante la práctica colectiva. Para ella, "el crew es como una familia, en la que uno decide pertenecer y estar con ella para crecer, con unos objetivos y visiones en común"

12. El Poblado o comuna 14 se encuentra ubicada en el suroriente de Medellín. Es la zona más exclusiva de la ciudad, y en ella predominan las residencias de los estratos 5 y 6. 
(BGirl-Bivi, comunicación personal, 05.2019). Por su parte, Feback y BBoy-Kapo señalan, sobre el crew:

E: ¿Qué es el crew?

K: Es como grupo.

E: ¿Qué características tiene el crew?

F: Es que un crew, no es como el grupo que tú haces, o sea, no es como el grupo de amigos con el que te ves todos los días. El crew es como el grupo disciplinado, el grupo que tiene unos objetivos y tiene una misionalidad con lo que hace, entonces, cuando tú hablas de un crew de grafitis, entonces, tú ya sabes que ellos tienen todo como para hacer una intervención como $\mathrm{crew}$, tienen toda una técnica para hacerlo... Cuando, por ejemplo, un $b$-boy, tienen todo una técnica para hacerlo, entonces se reconocen y tienen una obligación dentro del crew; entonces tú eres el encargado, es como una organización; yo creo que esa es la palabra, pero en lenguaje callejero es crew, pero cada uno tiene una obligación: tú eres el encargado de hacer la propuesta para presentarnos, usted se va a encargar de hablar con no sé quién, usted se va a encargar del espacio de la competencia y hacer los pasos de piso, usted del poder y ustedes se van a encargar de hacer las coreografías y las rutinas.

E: ¿Y cuál es la importancia o el significado que tienen las competencias?

F: No pues, a veces en las competencias es lo que yo te digo, en la competencia no se ve el proceso social comunitario, no tiene nada que ver, es que tienes que ser bueno, es un tema más de nivel artístico, ya lo que tú hagas comunitariamente... Por eso hay dos procesos: el de la industria, que es el que exige que tú seas reconocido, que tú seas bueno en esa disciplina, y ya, pues, lo comunitario, que es más lo pedagógico, lo metodológico.

E: ¿Individualiza la batalla?

F: No, antes une, yo creo, las batallas son importantes porque se reúnen, o sea, reúnen, son los únicos espacios que existen para poner en presente lo que has practicado durante todo el tiempo, entonces es como la ceremonia de graduación, como ceremonia de aceptación, tanto para raperos como para b-boys y como para DJs, o sea, tú te encargas de ensayar nueve horas a la semana, esas batallas tú vas a demostrar que has avanzado esas horas a la semana.

E: Es como retar tu nivel.

F: Es retar tu nivel, sí (Feback y BBoy-Kapo, comunicación personal, 07.2018).

En el crew o en el encuentro de diferentes crews, las prácticas de batallas y competencias son vividas de forma distinta a la promovida por las prácticas de competencia individualista. BGirl-Bivi compite en batallas de grupo, de parejas o 
individuales, y destaca la importancia de competir en la misma batalla con hombres y mujeres. La apertura, las posibilidades para la creatividad y la improvisación del espacio de la batalla permiten que cada competidor muestre su nivel, es un espacio que motiva para mejorar.

BGirl-Bivi y Feback valoran el estar en el mismo espacio de práctica con los hombres y, aunque reconocen la importancia de iniciativas entre mujeres, Feback, desde su experiencia de participación en Hip-hop al Parque, es crítica de algunos escenarios de tratamientos diferenciales:

F: En el año 2016, yo siempre había querido cantar en Hip-hop al Parque y yo dije: "Me voy a preparar muy bien, para presentarme a Hip-hop al Parque", y era como lo máximo, y: "voy a tener el mejor puntaje, porque quiero el mejor horario". Y yo me enfoqué, busqué apoyo en otros músicos, en amigas, no, jeso fue tan bonito...! Y llegamos a Hip-hop al Parque, pero pasó una cosa que fue superrayadora, y es que con toda la lucha que venía de generar mi propio espacio de participación y que no me vieran como un porcentaje que era lo que pasó con Rap Debate, como no hay mujeres, entonces nos tocó rellenarlo con lo que tengamos cerca, entonces la institución saca como: "Este año, Hip-hop al Parque cumple con su cuota femenina, con Feback", jel escenario de participación distrital! Y yo, cómo es posible que una institución pública, sabiendo que estamos tratando de generar, o sea, yo competí con los grupos de hombres, o sea, no había más raperas, eran sesenta raperos... ¿Por qué me venden así?, como una cuota del género del festival del distrito, sabiendo que competí con los hombres como si hubiese sido un hombre más, es como: pasaste por ser mujer, entonces para mí eso fue... Eso es lo que me aburre cuando no hay un reconocimiento, cuando el discurso también se vuelve violento, cuando el discurso también segmenta, entonces yo dije: "Bueno, listo, ellos quieren que yo haga una contrapropuesta..."

Entonces, yo empecé a hacer una contrapropuesta, y dije: "No, es que el hip-hop es una herramienta de transformación social, es una herramienta musical que hace parte de una industria cultural, si seguimos viéndonos como poblaciones, vamos a seguir siendo el relleno de todo, como la política, entonces subamos a rapear a un niño, para que cumplir la cuota de un niños; entonces pongamos una mujer negra, una mujer indígena", ¿si me entiendes? No puede ser así y menos en un discurso del distrito, y claro, nosotras llegamos y lo primero que yo hice fue mandar una carta de presentación que dice esto, y claro, todo el mundo dijo: “¿Cómo así?, entonces empezó a existir un movimiento de chicas que se llama hip-hop sin género, o sea, creo que funcionó, como que las mismas mujeres dijeron: "No, pero por qué yo no puedo cantar en una batalla de los gallos con los hombres, por qué tiene que hacer una batalla exclusiva de mujeres para que yo pueda cantar con otras mujeres, si yo también tengo nivel artístico para hacerlo", y por eso empezó mi lucha con el del evento del grafiti, con lo del evento del break, con los espacios de música, también empecé a ir a la escuela de rap feminista, les dije a ellas: "Yo les doy clases" (Feback, comunicación personal, 07.2018). 
Esta experiencia de Feback vuelve la atención sobre la intensa discusión, al interior del feminismo, sobre igualdad y diferencia, y genera cuestionamientos al derecho, acerca de la pertinencia de ciertas intervenciones que intentan superar las discriminaciones de género, a partir de la variación de cuotas. Feback expresa su malestar por la falta de igualdad en el tratamiento por parte del distrito, pues no fue a causa de un esencialismo de género que ella tomó parte del evento (por "ser mujer"), sino por la igualdad en su condición de artista. Incluso, al hacer referencia al "ser una población más", ella manifiesta lo problemático de las políticas focalizadoras, bajo las cuales se desdibuja la relación universal de derechos de la ciudadanía con el Estado, sin distinción de clase, género y etnia. El feminismo crítico (Arruzza; Batticharya; Fraiser, 2019) ha interpelado las políticas públicas de cuotas, pues terminan favoreciendo a unas cuantas mujeres y despolitizan la exigencia de transformación social para todas ${ }^{13}$.

La trayectoria de BGirl-Bivi al interior del hip-hop ha sido transgresora en diferentes sentidos. El rechazo en el campo clásico del ballet la llevó a explorar otros géneros, y terminar en uno donde la imagen dominante de la mujer se reconfigura. Esta búsqueda subjetiva de su lugar de mujer al interior del break la ha motivado, por ejemplo, a promover la comercialización de ropa para mujeres hopperas, que no quieren vestirse con camisetas extragrandes; o, en su momento, considerar una iniciativa de emprendimiento para madres hopperas, desde una plataforma digital. No obstante, el hecho de mayor ruptura con su origen de clase fue haber decidido llevar una vida de pareja con BBoy-Infinito, y entregar buena parte de su tiempo y esfuerzos al trabajo en el hip-hop de Infinitos Crew, lo que generó tensiones y diferencias con su familia:

\section{E: ¿Y tu familia cómo vio la decisión con el break?}

B: No, mi familia... terrible. Si mis papas decían: “¿Usted qué va a hacer con el baile?”.

Nunca pensaron... bueno ellos pensaban en danza clásica, contemporánea, usted no va a vivir de eso, pero cuando vieron que yo me fui por el hip-hop... Yo me acuerdo, cuando fui a Bucaramanga e hicieron un evento, ¿dónde quedaba...? Lastimosamente, pues la mayoría de los eventos de break dance, no son en un buen lugar, son en barrios populares. “¿Dónde queda el evento?”. “Por allá...”, yo les dije. Y me dijeron: “Te acompañamos”. Y yo: “Bueno, si quieren, iclaro!” Me acompañaron, fue en Girón, y fue en

13. A pesar de las formas históricas bajo las cuales se ha utilizado, de manera etnocéntrica y patriarcal, la universalidad abstracta, el feminismo crítico reconoce la existencia de una universalidad realista, de condiciones de opresión hacia las mujeres, generadas por el capitalismo. En tanto, las condiciones son universalmente compartidas, su camino de superación exige una transformación social total y no, simplemente, la mejora de condiciones para un pequeño grupo (Arruzza, 2017; Butler, 2000a; 200ob). 
un salón social. Cuando vieron los muchachos, cuando vieron el ambiente, de una me dijeron: “¿Usted qué hace aquí?, con esa gente, esto no es lo suyo, ¿cómo se le ocurre estar aquí”, que mire, que esos marihuaneros, que esos no sé qué...

Y yo, no lo son, lastimosamente se les tacha de eso porque una de las rama del hip-hop sí, en su mayoría lo son, pero nosotros para bailar, para hacer esto, no nos da para hacerlo... Es como yo les decía, un deportista es entrenamiento físico y mental, ellos decían que farrean que no sé qué, yo les dije: "Se acuestan temprano para madrugar a entrenar, entrenan en la mañana, entrenan en la noche". Y eso es otra de las cosas que es muy buena del break dance, que es lo que te digo, la disciplina, y todo lo que tiene uno que entrenar para poder lograrlo y sacar una secuencia, entonces es prácticamente como un deporte. El break dance ya entró en los Olímpicos en Argentina como un deporte, por la dificultad, por el entrenamiento que requiere... Entonces, yo les decía: "Lastimosamente no se desarrolla en los mejores barrios, pero no quiere decir que sean de marihuaneros". Yo creo que ellos pensaron que eso era una etapa mía... yo creo que nunca lo han terminado de aceptar.

E: ¿No lo han aceptado?

B: No, y cuando supieron que yo me ennovié con Juan, que bailaba, qué más hacía en la vida... Yo creo que ya se resignaron cuando nos casamos [risas].

E: ¿Qué sientes tú que el break le ha dado a tu vida?

B: Ya me dio todo [risas]. Primero, pues, lo más importante, fue que me llevó a conocer a Juan, que es hoy mi esposo y el papá de mi hija. Me llevó a tener familia también y conocer otro lado de la vida, porque, digamos, yo vengo como por el lado contrario de donde viene Juan. Yo, gracias a Dios, siempre fui de una familia con, no con mucho dinero, sino con, normal, siempre me pudieron dar todas las comodidades, estudié en un buen colegio, nunca tuve problemas de nada, nada... Y con él llegué a ver todo ese otro lado, el lado contrario, digamos, a todo lo que yo estaba acostumbrada, me llevó a chocar... Como que a veces uno está en una burbujita y me llevó a ver todo eso, y cómo son de diferentes las cosas, las personas, y a ver como toda esa parte de cómo puede uno, por medio del arte y por medio de lo que uno hace, llevar a los demás y también mejorar muchas cosas, porque uno estando en ese mundo también se cree, uno es más y no es así, y la personalidad, todo lo que me ha enseñado, todo lo que es como persona, entonces me ha ayudado a ser mejor persona (BGirl-Bivi, comunicación personal, 03.2018).

En el caso de BGirl-Bivi, ella potenció el componente organizativo de Infinitos Crew, desde sus conocimientos universitarios de la dinámica de los negocios, y se convirtió en una integrante central. Ella valora la posibilidad de poder aportar a los procesos organizativos y de transformación social impulsados desde el crew. De esta forma, el trabajo con el break dance desde el grupo, tiene para ella una dimensión 
artística, una colectiva y una profesional. Ella baila en el crew y, desde su formación profesional, ha aportado en el fortalecimiento de las relaciones institucionales y en la búsqueda de recursos para el sostenimiento del grupo:

\section{E: ¿Y en este momento?}

B: Sí, estamos llevando Infinitos mucho más profesional, realmente que no sea solamente un grupo de danza, sino realmente una empresa de arte y cultura. De hecho, el año pasado ganamos, con la EAFIT, un proyecto de emprendimiento cultural, quedamos en tercer lugar. El proyecto lleva un año en formación, ya definimos tres líneas de negocio, cada una con su marca representativa. La primera: formación. En esta línea se enmarcan los cursos, talleres y programas de entrenamiento, la marca líder de esta línea es el Feats Break, con la que estamos buscando desarrollar la primera plataforma web para el sector cultural. La segunda línea es proyección. En esta línea está todo lo que tiene que ver con las obras, shows, competencias y festivales de hip-hop, con su marca líder Infinitos Crew. Y la tercera línea es la escuela, donde se encuentra todo lo relacionado con nuestro proceso comunitario y social con niños y jóvenes en condición de vulnerabilidad, en diferentes ciudades del país, con quienes ya tenemos veinte años de experiencia, durante los que hemos logrado impactar a más de 7000 niños y jóvenes (BGirl-Bivi, comunicación personal, 03.2018).

Actualmente, BGirl-Bivi impulsa la plataforma virtual de Infinitos Crew a nivel nacional y se ocupa del cuidado de su hija. Su pareja, BBoy-Infinito, trabaja en el distrito, como profesor con contrato flexible, en programas de formación escolar en arte. Desde su trabajo en red con otros artistas de break dance y con su plataforma web, tienen presencia en diferentes ciudades del país como Medellín, Bogotá, Neiva, Ibagué y Barranquilla, en la que están iniciando un proceso con mujeres de Infinitos B-Girls.

En el flujo cotidiano de sus prácticas de trabajo, las mujeres hopperas y sus parejas establecen relaciones estratégicas con el Estado, las ONG y la industria, en busca de garantizar unas condiciones que les permitan vivir y hacer lo que les apasiona. El propósito de sus trabajos no es, simplemente, la generación de ingresos, sino también el desarrollo de procesos creativos y el aporte a dinámicas de transformación social. De esta forma, en las trayectorias estudiadas, se articulan de diversas maneras las dimensiones de la labor, el trabajo y la acción (Arendt, 2009) ${ }^{14}$. En condiciones de

14. De acuerdo con Arendt (2009), en la vida humana existen tres actividades fundamentales: la labor, el trabajo y la acción. La labor hace referencia al proceso biológico del cuerpo humano, relacionado con el imperativo de atender las necesidades vitales. El trabajo corresponde a la capacidad creadora del ser humano, a su potencial de generar productos que permanezcan más allá de la efímera existencia de la vida. Y la acción se relaciona con la capacidad de generar discurso y desplegar la vida política. 
limitación, las artistas populares se juegan la vida en sus labores de cuidado, en el trabajo creativo y en la promoción de procesos organizativos. En este sentido, sus trayectorias se inscriben en una dinámica de reproducción de la vida, en la que, de formas complejas, confluyen el trabajo de la reproducción social, el desarrollo subjetivo y el aporte a procesos de transformación en los territorios.

Las variadas relaciones que establecen las trabajadoras de hip-hop con las diferentes instituciones evidencian la complejidad de las prácticas artísticas que, toman lugar en la realidad de las relaciones de poder. El establecimiento de relaciones con el Estado y con las instituciones comerciales no hace más o menos "auténticas" las prácticas, pues no existe una cultura hip-hop puramente mercantilizada o genuinamente subversiva, sino que toma variadas formas y asume disputas en diferentes grados $^{15}$. La vida real, con sus contingencias y necesidades cotidianas, complejiza las miradas puristas. Como señalan los relatos, Infinitos Crew ha sido una alternativa de sentido para diversos jóvenes en San Javier, desde su sostenimiento con proyectos del Estado e iniciativas de emprendimiento que, en todos los casos, ante la ausencia de reconocimiento de lxs artistas como trabajadorxs y como ciudadanxs, descargan todos los riesgos de su protección social en la responsabilidad individual.

Ante la dificultad de generar empresa en Colombia, el trabajo colectivo que se gesta al interior de procesos organizativos como "Hip-hop libre de sexismos" o en Infinitos Crew ha posibilitado el sostenimiento de iniciativas artísticas populares, en condiciones de total precarización del trabajo.

\section{Conclusiones}

A partir de las dos historias de vida estudiadas, podemos precisar algunas conclusiones de la experiencia metodológica y el análisis que se derivó de las lógicas de trabajo articuladas en las trayectorias de las artistas.

A nivel metodológico, primero, destacamos que toda trayectoria de trabajo toma lugar en espacios-tiempos concretos. En tal sentido, es necesario comprender los contextos y círculos sociales en los que se desarrolla, pues se presentan procesos recíprocos de configuración de la trabajadora y su contexto. En la investigación, se logró ver con claridad la relación de Feback y el barrio, así como de BGirl-Bivi y el crew. A su vez, entre los círculos sociales (Estado, ONG, crew, familia), se tejen relaciones de diferente tipo (cooperación, cooptación, competencia) que complejizan el análisis de las condiciones y lógicas laborales.

15. Las entrevistas realizadas por Zadie Smith (2003; 2012) a los raperos Eminen y Jay Z dejan a la luz las contradicciones en la vida de estos artistas, en sus diversas relaciones con el campo de poder. 
En segundo lugar, identificamos la imposibilidad de homogeneizar las trayectorias de trabajo en términos de clase. Se puede llegar a lugares cercanos en el espacio social (BGirl-Bivi y B-Boy Infinito), desde trayectorias diferentes; $y$, aunque se compartan características en cuanto a condiciones de origen, las experiencias pueden variar, lo que puede verse en el contraste de la relación con el barrio de BBoy-Kapo y Feback. Una tercera reflexión metodológica tiene que ver con la investigación de subjetividades de mujeres desde las historias de vida, que nos permitió acercarnos a dos búsquedas subjetivas que se inscriben en la misma cultura hip-hop, pero que han llegado a esta desde trayectorias diferentes. Esto evidencia la diversidad de la experiencia en mujeres que comparten el mismo campo de trabajo.

Respecto a los hallazgos que pueden aportar para repensar el derecho laboral, primero, advertimos la necesidad de ampliar la comprensión del trabajadxr y de su ciudadanía social, más allá del modelo androcéntrico del obrero de la fábrica. La comprensión clásica se fundamenta en una falsa separación entre trabajo productivo y reproductivo, que invisibiliza el proceso de producción de la vida que hay detrás del trabajadxr formal, del que hace parte: la alimentación, el vestido, el cuidado de los hijos y el cuidado de los adultos mayores. En este trabajo de producción del trabajadxr, toman parte también: la educación, la vivienda y el transporte público (Bhattacharya, 2017). Comprender que la producción del trabajador por fuera del espacio formal implica estas dimensiones, permite ver la relación directa entre la realización del derecho al trabajo y la provisión de los bienes públicos.

Un segundo hallazgo de la investigación, en términos de derecho laboral, remite a las condiciones de precarización del trabajo de las artistas populares. En el caso de las historias de vida estudiadas, tanto el trabajo productivo como reproductivo es asumido por las mujeres, sin garantías de protección social. Las artistas ejercen también labores de cuidado y, en su condición de trabajadoras, enfrentan una doble desvalorización como artistas y como cuidadoras. A su vez, desde el discurso del emprendimiento promovido por el Estado y las ONG, las trabajadoras asumen, subjetivamente, un lugar de empresarias, en el que la responsabilidad de provisión de los derechos sociales queda en la esfera de lo individual.

Un tercer hallazgo tiene que ver con la diversidad en términos de clase, género y oficios del trabajo en la ciudad. Esta diversidad genera preguntas acerca de la relación entre el derecho al trabajo y el derecho a la ciudad (Harvey, 2013), que vuelven la atención a las preocupaciones clásicas bajo las cuales surgió el derecho laboral: las relaciones de propiedad y el acceso a la riqueza social. Lxs trabajadorxs populares que laboran en lugares diferentes a la fábrica interpelan a la administración pública desde su derecho a habitar y recrear la ciudad con su trabajo. Esto demanda habilitar las condiciones para que, como ciudadanxs, puedan participar en el diseño de 
políticas públicas que garanticen su derecho a acceder a los recursos públicos de la ciudad y a gozar del espacio urbano.

Finalmente, el estudio de las trayectorias de artistas populares en las que la producción creativa atraviesa sus itinerarios, nos recuerda la comprensión del trabajo como actividad vital, de realización subjetiva y dinamización de procesos sociales. Considerar a profundidad las transformaciones que requiere el derecho laboral implica ampliar su concepción del trabajo hacia su dimensión vital. Esto conlleva articular la discusión acerca de su sentido, en la tensión entre la garantía de los intereses del mercado o los de la reproducción de la vida.

\section{Referencias}

Ahmad Khan, Syed (2018). Struggles and Actions for Legal Space in the Urban World: The Case of Informal Economy E-waste Workers. Canadian Journal of Law as Society, 33, 115-135.

Arendt, Hannah (2009). La condición humana. Bogotá: Paidós.

Arias, Camilo (2014). The Universal Zulu Nation in Colombia: Social Impact of Hip-hop Culture in the Valley of Aburrá. Kavilando, 6, 179-184.

Arruzza, Cinzia (2017). Capitalism and the Conflict over Universality: A Feminism Perspective. Philosophy Today, 61(4), 847-861.

Arruzza, Cinzia; Bhattachrya, Tithi; Fraser, Nancy (2019). Feminism for the 99\%. A manifesto. Londres: Verso.

Barry, Andrew; Osborn, Thomas; Rose, Nikolas (1996). Foucault and Political Reason: Liberalism, Neo-Liberalism and Rationalities Government. Chicago: University of Chicago Press.

Benzason, Kate; Luxton, Meg (2006). Social Reproduction. Montreal: MacGill Queen's University.

Bhattachrya, Tithi (2017). Mapping Social Reproduction Theory. En Social Reproduction Theory Remapping Class, Recentering Oppression (pp. 1-19). Londres: Pluto Press.

Blackett, Adelle (2018). Vers un droit du travail décolonisé: contributions au droit transnational du travail en émergence. Revue Canadienne Droit et Société, 33(2), 111-114.

Bourdieu, Pierre (1999). La miseria del mundo. Buenos Aires: FCE.

Butler, Judith (20ooa). Competing Universalities. En Contingency Hegemony Universality (pp. 136-181), editado por Judith Butler; Ernesto Laclau; Slavoj Zizek. Londres: Verso. 
Butler, Judith (200ob). Restaging the Universal: Hegemony and the Limits of Formalism. En Contingency Hegemony Universality (pp. 11-43), editado por Judith Butler; Ernesto Laclau; Slavoj Zizek. Londres: Verso.

Carrasco, Cristina (2014). La economía feminista: ruptura teórica y propuesta política. En Con voz propia la economía feminista como apuesta teórica y política (pp. 25-48). Madrid: La Oveja Roja.

Castel, Robert (2009). El ascenso de las incertidumbres. México: FCE.

Centro Nacional de Memoria Histórica (2011). La huella invisible de la guerra: desplazamiento forzado en la Comuna 13. Bogotá: Ediciones Semana.

Federici, Silvia (2013). Revolución en punto cero: trabajo doméstico reproduccióny luchas feministas. Madrid: Traficantes de Sueños.

Ferguson, James; Gupta, Akhil (2002). Spatializing States: Toward an Ethnography of Neoliberal Governmentality. American Anthropological Association, 29, 981-1002.

Ferguson, Susan (2017). Children, Childhood and Capitalism: A Social Reproduction perspective. En Social Reproduction Theory Remapping Class, Recentering Oppression (pp. 112-130), editado por Tithi Bhattachayra. Londres: Pluto Press.

Ginzburg, Carlo (2007). Reflexiones sobre una hipótesis: el paradigma indiciario. Contrahistorias. La otra mirada de Clío, 4(7), 7-16.

Ginzburg, Carlo (2016). El queso y los gusanos: el cosmos según un molinero del siglo XVI. Buenos Aires: Ariel.

Grignon, Claude; Passeron, Jean Claude (1991). Lo culto y lo popular: miserabilismo y populismo en sociología y literatura. Buenos Aires: Nueva Visión.

Hall, Stuart (1984). Notas sobre la deconstrucción de “lo popular”. En Historia populary teoría socialista (pp. 185-198), editado por Ralph Samuel. Barcelona: Crítica.

Harvey, David (2013). Ciudades rebeldes: del derecho a la ciudad a la revolución urbana. Madrid: Akal.

Higgins, Dalton (2009). Hip-hop World. Toronto: Groundwork Books.

Levi, Giovanni (1990). La herencia inmaterial: la historia de un exorcista piamóntes del siglo XVII. Madrid: Nerea.

Levi, Giovanni (2003). Los usos de la biografía. Temas Socio-jurídicos, 44, 139-151.

Morss, Elliott (1984). Institutional Destruction Resulting from Donor and Project Proliferation in Sub-Saharian African Countries. World Development, 12, 465-470.

Noirier, Gérard (2011). Introducción a la sociohistoria. Madrid: Siglo XXI. 
Passeron, Jean Claude (2011). El razonamiento sociológico: el espacio comparativo de las pruebas históricas. Madrid: Siglo XXI.

Passeron, Jean Claude; Revel, Jacques (2005). Penser par cas. París: Enquête.

Ramírez-Suárez, Yenny Carolina (2012). El problema de la individualidad en Simmel. En George Simmely la modernidad (pp. 267-276), editado por Clemencia Tejeiro. Bogotá: Universidad Nacional de Colombia.

Revel, Jacques (1996). Jeux d'echelles: la micro-analyse à l'experience. París: Gallimard.

Rodríguez, Corina (2015). Economía feminista y economía del cuidado: aportes conceptuales para el estudio de la desigualdad. Nueva Sociedad, 256, 230-244.

Smith, Zadie (2003). The zen of Eminem. Five Dials. Recuperado de https://fivedials.com/ reportage/the-zen-of-eminen-zadie-smith/

Smith, Zadie (2012). The House that Hova Built. Recuperado de https://www.nytimes. com/2012/o9/o9/t-magazine/the-house-that-hova-built.html

Vargas, Alejo (1992). Colonización y conflicto armado: Magdalena Medio santandereano. Bogotá: CINEP.

Weber, Florence; Beaud, Stéphane (2010). Guide de l'enquête de terrain. París: La Decouvérte. 